This letter was shown to the authors, who reply as follows:

In our study the diagnosis of hypertrophic cardiomyopathy was not based on the classical features of asymmetrical septal hypertrophy and left ventricular outflow tract obstruction but was made in the presence of left ventricular hypertrophy of unknown aetiology. Exclusion of hypertension is the greatest problem when studying hypertrophic cardiomyopathy, and a deliberate attempt was made to do this and to exclude other secondary causes of left ventricular hypertrophy.
We would not wish to draw definitive con lusions from our work but could not help by being impressed that none of our patients died during a thi ee $y \mathrm{ca}$; period. We believe that this does warrant fu the: investigation and study since we agree with $D \cdot r / a t t$ and Newcombe that if other authors find simi!ar results to our own this would greatly alter the avi'nde to the disease of both physicians and patients.
Dr L M Shapiro,
National Heart Hospital,
Westmoreland Street,
London WIM 8BA.
Dr A Zezulka,
Dudley Road Hospital, Birmingham 18

\title{
Morphological appearance of atherosclerotic lesions of the coronary arteries
}

Sir,

Pidgeon et al (1984; 51: 125-9) correctly point out that "coronary atheroma is present more often and is more widely distributed in the coronary tree than is indicated by coronary angiography." Perhaps your readers would be interested in the following historical facts.

My teacher, H Gideon Wells, professor of pathology, University of Chicago, taught that the collapsed coronary artery seen at necropsy was frequently inconsistent with either the clinical history or the state of the myocardium. For this reason "In order to determine the configuration of the lesions of the coronary arteries under living conditions, they were examined roentgenologically when distended with an injection mass of a suspension of barium sulfate, Tragacanth and water at mean aortic pressure." $\mathrm{He}$ subsequently published ${ }^{1}$ illustrations showing the differences between the postmortem collapse of the coronary vessel at the site of an atherosclerotic lesion and the appearance of the same region of the coronary vessel when it distended with contrast substance. He concluded that one must take into consideration these changes when evaluating findings at necropsy.
It was Thoma's ${ }^{2}$ concept that medial atrophy produced dilatation of the vessel at the site of atherosclerosis which lead Wells to perform his experiments proving the correctness of Thoma's brilliant concept of the morphological appearance of the atherosclerotic lesion in the living.

Louis A Soloff,

Division of Cardiology,

Temple University Health Sciences Center, Philadelphia, Pennsylvania 19140, USA

\section{References}

1 Stewart JD, Birchwood E, Wells HG. The effect of atherosclerotic plaques on the diameter of the lumen of coronary arteries. FAMA 1935; 104: 731-3.

2 Thoma R. Ueber die Abhängigkeit der Bindegewebsneubildung in der Arterienintima von den mechanischen Bedingungen des Blutumlaufes. Archiv für pathologische Anatomie und Physiologie, und für klinische medicin 1886; 104: 209-41.

\section{Notices}

\section{Pediatric Cardiology}

The Second World Congress of Pediatric Cardiology will be held from 2 to 6 June 1985 at the Waldorf Astoria Hotel, New York. Further information may be obtained from: Virginia Herlitz, 404 Park Avenue South, New York, NY 10016, USA.

\section{British Cardiac Society}

The Autumn Meeting will be held at the Wembley Conference Centre, London, on 3 and 4 December 1984 , and the closing date for receipt of abstracts will be 15 August 1984.

The Annual General Meeting for 1985 will take place in Birmingham on 17 and 18 April 1985, and the closing date for receipt of abstracts will be 8 January 1985. 